\title{
Restaurant Revenue Management at Chevys: Determining the Best Table Mix
}

\author{
Sheryl E. Kimes \\ Corresponding Author \\ Cornell University \\ Gary M. Thompson \\ Cornell University
}

\section{ABSTRACT}

Revenue management has been used in a variety of industries and generally takes the form of managing demand by manipulating length of customer usage and price. Supply mix is rarely considered, although it can have considerable impact on revenue. In this research, we focused on developing an optimal supply mix, specifically on determining the supply mix that would maximize revenue. We used data from a Chevys restaurant, part of a large chain of Mexican restaurants, in conjunction with a simulation model to evaluate and enumerate all possible supply (table) mixes. Compared to the restaurant's existing table mix, the optimal mix is capable of handling a $30 \%$ increase in customer volume without increasing waiting times beyond their original levels. While our study was in a restaurant context, the results of this research are applicable to other service businesses.

\section{Subject Areas: Capacity Planning, Case Study, Revenue Management, Service Operations, and Simulation.}

\section{INTRODUCTION}

Revenue management has been widely adopted in the airline, hotel, and rental car industries (Smith, Leimkuhler, \& Darrow, 1992; Hanks, Noland, \& Cross, 1992; Carroll \& Grimes, 1995), but has only recently gained attention in the restaurant industry (Kimes, Chase, Choi, Ngonzi, \& Lee, 1998; Kimes, 1999; Kimes, Barrash, \& Alexander, 1999). Companies using revenue management have reported revenue increases of 2\% to 5\% (Smith et al., 1992; Hanks et al., 1992), and even though the restaurant industry has a higher variable cost percentage than traditional revenue management industries, potential revenue gains can be substantial.

Revenue management is a form of capacity management in which demand and supply are managed by manipulating length of usage and price (Kimes \& Chase, 1998). Most revenue management applications and research have focused on managing demand, while the focus of this work is on managing supply. If a company has the wrong mix of supply (e.g., a restaurant has the incorrect mix of tables of different sizes or a sports arena has a poor mix of sections), its revenue management efforts will produce suboptimal results. The intent of our research is to determine the revenue impact of an optimal supply mix. We do so in a restaurant context, although the concepts and methods presented could be readily applied to other industries. Chevys, a chain of 100+ Mexican restaurants, agreed to work with us and provided us with data from one of their restaurants. We used their data in conjunction with a table mix simulation model to determine the optimal mix of tables that would maximize restaurant revenue.

We will first discuss revenue management in general, and then present various revenue management performance 
measurements. Subsequently, we will discuss supply planning and its impact on revenue management. Following this, we will discuss the baseline performance at Chevys including seat occupancy, revenue measures, party size composition, and meal time duration. We will then present our simulation model and discuss our modeling results and Chevys' successful implementation of our findings.

\section{REVENUE MANAGEMENT}

Revenue management is the application of information systems and pricing strategies to allocate the right capacity to the right customer at the right place at the right time. The determination of "right" entails achieving both the most contribution possible for the restaurant while also delivering the greatest value or utility to the customer. In practice, revenue management has meant setting prices according to predicted demand levels so that price-sensitive customers who are willing to purchase at off-peak times can do so at favorable prices, while price-insensitive customers who want to purchase at peak times will be able to do so. The application of revenue management has been most effective when it is applied to operations that have relatively fixed capacity, demand that is variable and uncertain, perishable inventory, appropriate cost and pricing structure, and varying customer price sensitivity. Those attributes are found in the restaurant industry.

Revenue management research in the airline and hotel industries has primarily focused on different allocation methods for developing future rate and availability controls for a relatively fixed inventory mix (e.g., Belobaba, 1989; Baker \& Collier, 1999; McGill \& van Ryzin, 1999). Required inputs include forecasts for different predetermined fares (rates) for different lengths of usage (origin-destination, flight legs, or length of stay; Littlewood, 1972; Weatherford, 1995; Wickham, 1995; Weatherford \& Kimes, 2003) and overbooking levels. Other research has addressed the issues of pricing (i.e., the optimal prices to charge) and customer choice behavior (Gallego \& van Ryzin, 1994; Bertsimas \& Perakis, 2001).

The literature on restaurant revenue management is fairly recent (Kimes et al., 1998; Kimes, 1999) and almost all articles have focused on arrival (Thompson, 2002, 2003; Bertsimas \& Shioda, 2003; Kimes \& Thompson, 2003) and duration (Kimes et al., 1999, 2002; Kimes, 2004) control. Pricing, although an important aspect of any revenue management strategy, has received limited attention (Kimes \& Wirtz, 2002, 2003). Because the focus of our research is on the optimal table mix, an important element of any arrival control strategy, the articles on arrival control are the most relevant.

Some restaurants cater solely to walk-in business and others serve both parties with reservations and walk-ins. A restaurant that takes only walk-ins must decide if, where, and when to seat different-sized parties. The issue becomes one of the appropriate table at which to seat the party. For example, if a party of two is seated at a table for four (referred to as a 4-top), the revenue-producing capacity of the remaining two seats is lost. Specifically, the restaurant must decide when to save tables for larger parties even when smaller parties are waiting.

Bertsimas and Shioda (2003) developed and tested three different models (integer programming, stochastic integer programming, and approximate dynamic programming (ADP)) for restaurants that do not accept reservations. They tested each model with four different nesting models and a bid price model at three different demand intensities (68\%, 93\%, and 154\%) for constant and varied arrival rates. They found that Full Nesting worked better than other nesting approaches 
and that revenue increased as the complexity of the mathematical model increased. The ADP model worked best for all scenarios and achieved higher revenue without an increase in waiting time.

While their research is interesting, many of their assumptions need further testing. They assumed that revenue per customer increases as the size of the party increases, that the maximum waiting time does not vary by party size, that all parties and table sizes were even numbers, and that the table mix was fixed. In addition, they only tested two derived arrival patterns (constant and varying with larger parties arriving later) in a small (38-seat) fictional restaurant.

Thompson $(2002,2003)$ studied the issue of table combinability and found that combinable tables lead to higher revenue in smaller restaurants with larger mean party sizes, but that dedicated tables lead to higher revenue in other restaurants. He also found that, for restaurants using combinable tables, the revenue effect of good table mixes far exceeds the revenue effects resulting from different layouts of the same table mix. This research will be described in more detail below.

Kimes (2004) presented the application of revenue management to a 230-seat Chevys Freshmex restaurant, discussed the baseline performance of the restaurant (seat occupancy, revenue per available seat hour, party mix, meal duration), the strategies developed (improved table mix and service delivery improvements), the implementation process and the results achieved. By implementing an improved table mix and improving the service delivery process, the restaurant was able to increase revenue. We used the data from this restaurant for our research.

Because most research (with the exception of Thompson $(2002,2003)$ and Kimes (2004)) considers the supply mix to be fixed, a suboptimal solution will be achieved if the supply mix does not closely match the mix of demand. For example, if an airline does not have an optimally sized business class, it may end up turning away passengers who wish to purchase a business class seat or may end up upgrading lower-paying economy class passengers to business class. Some European airlines have developed a low-technology approach for addressing this problem. They simply use a moveable curtain to distinguish between the two classes of service. The airlines leave an empty seat between people seated in the Economy-class seats that end up in the business class section (and provide the same level of food and beverage service as they provide to their other business class customers). If demand for business class is low, business class becomes smaller, and conversely if demand is high, business class becomes larger. In restaurants, capacity flexibility is provided by tables that can be combined to seat larger parties. Or, some self-storage firms rent flexible space in which the size of the space can be customized to customer requirements. These examples serve to highlight the importance of designing service capacity in a way that facilitates the use of the flexible capacity.

Whether or not a restaurant has flexible capacity, if it can ensure that its table mix closely matches the party size composition of their customers, it will achieve higher seat occupancies and thus higher overall revenue. While some restaurants (most notably fine dining restaurants) use reservations to help manage their seat occupancy, the majority of U.S. restaurants do not take reservations and instead rely on walk-in business. This reliance on walk-in business makes the optimal table mix even more important. We decided to focus our efforts on determining the optimal table mix for a restaurant. To do this, we first examined the supply planning problem. 


\section{SUPPLY PLANNING}

The supply planning problem can be divided into four parts: the number of facilities, the facility size, the supply mix, and the flexibility of the supply mix. The first two questions, the number of facilities and the size of each facility, are often addressed in the capacity planning literature (Sasser, 1976; Lovelock, 1992; Ng, Wirtz, \& Lee, 1999; Klassen \& Rohleder, 2001), but typically not from a revenue management standpoint. For example, companies must first decide how many units to operate and then determine the size of each unit. Subsequently, it must decide on the mix of that capacity and the desired flexibility. Making these decisions simultaneously, instead of consecutively, can yield more profitable outcomes, though doing so greatly increases the complexity of the problem.

Interestingly, the topic of supply mix has received very little attention in the literature. Capacity planning research focuses on how best to match supply with demand but tends to concentrate more on developing supply levels that meet demand at a minimum cost. The mix of supply is rarely considered, rather the amount of supply is emphasized. Revenue management research focuses on maximizing revenue by managing demand, but does not typically consider the impact of supply mix.

\section{AMOUNT OF SUPPLY AND SIZE OF OUTLETS}

The capacity planning literature addresses the issue of the optimal amount of supply (or capacity) that a firm should have to meet customer demand. In a restaurant setting, these decisions are the number of restaurants to build or acquire and the size of each restaurant. Restaurant size is often inversely related to customers' willingness to travel. Restaurants that offer a unique experience-whether it is the food, the setting, or both-are those that can draw customers from larger areas and so fewer, larger restaurants are desirable. By contrast, customers are less willing to travel to restaurants that offer a commoditized food item (such as fast-food restaurants). In this case, a larger number of small restaurants is typically preferable. The restaurant that we consider falls somewhere in the middle of the continuum: the experience and food are not as common as that existing in fast-food restaurants, but it is not a particularly unique dining experience, either. Thus, in the restaurant setting, size can be determined by concept, and so the size decision may precede the decision about number of locations.

\section{SUPPLY MIX}

Because most revenue management research (with the exception of Thompson $(2002,2003)$ and Kimes (2004)) considers the supply mix to be fixed, a suboptimal revenue solution will be achieved if the supply mix does not closely match the mix of demand. For example, if an airline does not have an optimally sized business class, it may end up turning away passengers who wish to purchase a business class seat or may end up upgrading lower-paying economy class passengers to business class.

The optimal supply mix can have considerable revenue impact. For example, in the airline industry, the optimal mix of plane sizes can help an airline operate more efficiently and increase profitability, or in the hotel industry, the optimal mix of room types can greatly affect the financial results achieved. While revenue management research has concentrated 
on the most profitable way in which to allocate demand to available supply, we have found very little research, with perhaps the exception of the flight assignment program (Rexing, Barnhart, Kniker, Jarrah, \& Krishnamurthy, 2000), that addresses the optimal mix of supply. Other industries face similar supply mix problems. For example, self-storage facilities must decide on the optimal mix of different size storage spaces, and performing arts centers and stadiums must decide on the optimal partition of seats to different market segments. The optimal supply mix is affected by the physical space required for each inventory unit, by the relative comfort and attractiveness of the supply mix and by its ease of use.

\section{SUPPLY FLEXIBILITY}

Companies have two ways in which they can create flexibility in their physical supply: through combinable units of inventory and through customer upgrades and downgrades.

Combinable inventory units, for example, combinable tables in a restaurant, combinable rooms in a hotel, or movable partitions on airlines, can give companies flexibility in matching their supply to their demand mix. For example, a restaurant can combine two tables of two to accommodate a party of four, or an airline can move the partition between first class and economy to adjust the numbers of seats in each class of service.

Thompson (2002) studied the impact of table combinability. Specifically, he studied whether it is more profitable to have tables dedicated to serving parties of a particular size (i.e., parties of 1 or 2 can be served at 2-tops, parties of 3-4 can be served at 4-tops) or whether the restaurant should use tables that can be combined as needed based on party size. He used simulation to study the impact of using five levels of combinability $(0 \%, 10 \%, 30 \%, 50 \%$, and $100 \%)$ in two different restaurant sizes (50 and 200 seats) for three different mean party sizes (2.5, 3.5, and 4.5 people). He assumed a constant dining time and per person check average for all sized parties, a maximum tolerable wait of 90 minutes and assigned the next available table to the largest waiting party. He also assumed that the restaurant had already adopted an optimal table mix and that the decision had become one of the best mix of dedicated and combinable tables to use. He found that combinable tables worked better only for smaller restaurants with small mean party sizes and that dedicated tables worked best for all other restaurants. This outcome can be explained by the loss of productivity that occurs when some tables are held out of service until adjacent tables become available (so that the tables can be combined to seat a large party). In later research (2003), he studied the optimal configuration of combinable tables and found that better configurations used longer sequences of smaller combinable tables and that effective configurations could result in a $1.4 \%$ improvement in revenue.

Customer upgrades and downgrades can be used to manipulate demand to better match the supply mix. While upgrades are not specifically a supply mix approach, they allow a firm to ameliorate the effect of an inappropriate supply mix. For example, airlines can upgrade selected economy passengers to first class and then sell the vacated economy seats to other customers. Essentially, this is a situation when there is excess demand for one type of supply (in this case, economy seats) and excess supply for another type of supply (in this case, first-class seats). Similar behavior is seen in the car rental industry (Carroll \& Grimes, 1995), the hotel industry, and cruise industry. Downgrades (in which a person is transferred to a lower class of service) are also possible, but are often avoided due to the potential negative impact on 
customer satisfaction.

\section{SUPPLY PLANNING APPLICATIONS}

To address these questions for any industry, a detailed understanding of the unit of inventory and the unit of time used in that industry is necessary. For example, hotels sell rooms for a certain number of nights, restaurants sell seats for a certain number of minutes or hours, and car rental companies rent cars for a certain number of days or weeks.

The most commonly used performance metric in revenue management is Revenue per Available Time-Based Inventory Unit (RevPATI). For example, hotels measure Revenue per Available Room-Night, restaurants measure Revenue per Available Seat-Hour (RevPASH), and car rental companies measure Revenue per Available Car-Day. RevPATI gives a good indication of both capacity utilization and of revenue generation.

Figure 1 presents supply mix questions and factors in a variety of industries. For example, self-storage companies rent space (generally measured as the number of square feet or square meters) for a certain length of time (generally measured in months). Self-storage operators must first decide on the number of locations to operate and then must determine the number of spaces to have in each facility. The next questions are to decide how many of each sized space each facility should have and the desired flexibility of those spaces.

Figure 1: Supply mix factors in various industries. The supply mix questions remain the same, but their answers vary depending on the industry.

\begin{tabular}{|c|c|c|c|c|c|c|c|}
\hline & Hotel & Restaurant & Self-Storage & Stadium/Arena & Theater & Car Rental & Airline \\
\hline $\begin{array}{l}\text { Number } \\
\text { of } \\
\text { facilities }\end{array}$ & $\begin{array}{r}\text { How } \\
\text { hot }\end{array}$ & How & How & & & \begin{tabular}{|c|} 
How many \\
car rental \\
locations? \\
\end{tabular} & \begin{tabular}{|c|} 
How many \\
airports \\
served? \\
\end{tabular} \\
\hline \multirow[t]{2}{*}{$\begin{array}{l}\text { Facility } \\
\text { size }\end{array}$} & $\begin{array}{c}\text { How many } \\
\text { rooms in each } \\
\text { hotel? } \\
\end{array}$ & $\begin{array}{l}\text { How } \\
\text { seats i } \\
\text { restau }\end{array}$ & $\begin{array}{l}\text { How } \\
\text { spac } \\
\text { each }\end{array}$ & $\begin{array}{r}\text { How } \\
\text { seats } \\
\text { stadiun }\end{array}$ & $\begin{array}{r}\text { Hov } \\
\text { seats } \\
\text { the }\end{array}$ & $\begin{array}{c}\text { How many } \\
\text { cars at } \\
\text { each rental } \\
\text { location? }\end{array}$ & $\begin{array}{c}\text { How many } \\
\text { flights for } \\
\text { each city } \\
\text { pair? } \\
\end{array}$ \\
\hline & $\begin{array}{l}\text { How many of } \\
\text { each type of } \\
\text { room (i.e. } \\
\text { suites, } \\
\text { doubles, } \\
\text { kings)? }\end{array}$ & $\begin{array}{c}\text { How many of } \\
\text { each table } \\
\text { size (i.e. 2- } \\
\text { tops, 4-tops)) }\end{array}$ & $\begin{array}{l}\text { How many of } \\
\text { each unit size } \\
(1 . e .10 \times 10 \text {, } \\
5 \times 10) ?\end{array}$ & $\begin{array}{l}\text { How many } \\
\text { seats in each } \\
\text { section (i.e. } \\
\text { loge, field } \\
\text { box)? }\end{array}$ & $\begin{array}{c}\text { How may } \\
\text { seats in each } \\
\text { section (i.e. } \\
\text { orchestra, } \\
\text { loge, } \\
\text { mezzanine)? }\end{array}$ & $\begin{array}{c}\text { How many } \\
\text { of each car } \\
\text { type (i.e. } \\
\text { sub- } \\
\text { compact, } \\
\text { compact, } \\
\text { mid-sized)? }\end{array}$ & \begin{tabular}{|} 
How many \\
seats in \\
each \\
section (i.e. \\
first class, \\
business \\
class, \\
economy)? \\
\end{tabular} \\
\hline \begin{tabular}{|l|} 
Supply \\
flexibility
\end{tabular} & $\begin{array}{c}\text { Room } \\
\text { Combinability, } \\
\text { Upgrades }\end{array}$ & $\begin{array}{r}\text { Tat } \\
\text { Combir }\end{array}$ & $\begin{array}{r}\text { Sp } \\
\text { Combi } \\
\text { Upgi }\end{array}$ & $\begin{array}{r}\text { Se } \\
\text { Comb } \\
\text { Upg }\end{array}$ & $\begin{array}{r}\text { Se } \\
\text { Comb } \\
\text { Up }\end{array}$ & $\begin{array}{r}\mathrm{Tr} \\
\text { an } \\
\text { Loce } \\
\text { Upg } \\
\end{array}$ & $\begin{array}{l}\text { Mo } \\
\text { part } \\
\text { upg }\end{array}$ \\
\hline \begin{tabular}{|l|} 
Unit of \\
Inventory \\
\end{tabular} & & & oot & & Seat & & Seat \\
\hline \multirow{2}{*}{\begin{tabular}{|l|} 
Unit of \\
Time \\
Revenue \\
per \\
Available \\
Time- \\
Based \\
Inventory \\
Unit \\
\end{tabular}} & bt & & 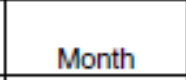 & $\theta$ & 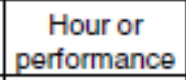 & & \\
\hline & \begin{tabular}{|c|} 
\\
Revenue per \\
Available \\
Room Night \\
(RevPAR) \\
\end{tabular} & \begin{tabular}{|c|} 
Revenue per \\
Available \\
Seat Hour \\
(RevPASH) \\
\end{tabular} & \begin{tabular}{|} 
Revenue per \\
Available \\
Square Foot \\
per Month \\
(RevPASM)
\end{tabular} & \begin{tabular}{|c|} 
Revenue per \\
Available Seat \\
per Game \\
(RevPASG)
\end{tabular} & \begin{tabular}{|c} 
Revenue per \\
Available \\
Seat per \\
Performance \\
(RevPASP)
\end{tabular} & $\begin{array}{c}\text { Revenue } \\
\text { per } \\
\text { Available } \\
\text { Car Day } \\
\text { (RevPACD) }\end{array}$ & \begin{tabular}{|c|} 
Revenue \\
per \\
Available \\
Seat Mile \\
(RevPASM)
\end{tabular} \\
\hline
\end{tabular}


Similarly, restaurants generally sell seats (although not explicitly) for a certain length of time. Restaurant chains must decide on the number of restaurants that should be operated, and determine the best size for the individual restaurants. Once these decisions have been made, the questions become one of the optimal mix of tables and the desired flexibility of those tables.

\section{RESEARCH PROBLEM}

In this article, we use simulation to develop an optimal table mix for a 230-seat restaurant. While we apply our model in a restaurant context, it could easily be applied to other problem settings such as airlines, hotels, performing arts centers, and sports arenas. If an optimal supply mix can be developed and adopted, a company can greatly increase its revenue-generating ability. The current article differs from earlier published work in that we are focused on an actual success story of the search for an optimal supply mix. We hope that this success leads credence to the importance of pursuing optimal supply mixes in other restaurants and in other service settings.

\section{PROBLEM SETTING}

Chevys, a large Mexican restaurant chain, was interested in applying revenue management to their restaurants. We concentrated on one of their restaurants that was located in a shopping mall in a large Southwestern city. The restaurant,

Table 1: Revenue per available seat hour (RevPASH) was calculated by dividing the total revenue during a particular day of week and hour by the number of days and number of seats.

\begin{tabular}{lccccccccccc}
\hline & \multicolumn{10}{c}{ Hour of Day } \\
\cline { 2 - 11 } & 11 & 12 & 13 & 14 & 15 & 16 & 17 & 18 & 19 & 20 & 21 \\
\hline Sunday & $\$ 2.42$ & $\$ 4.73$ & $\$ 5.71$ & $\$ 4.37$ & $\$ 2.76$ & $\$ 3.17$ & $\$ 4.13$ & $\$ 3.80$ & $\$ 2.07$ & $\$ 0.59$ & $\$ 0.00$ \\
Monday & $\$ 2.06$ & $\$ 2.67$ & $\$ 2.70$ & $\$ 1.96$ & $\$ 1.20$ & $\$ 1.14$ & $\$ 3.10$ & $\$ 4.14$ & $\$ 2.17$ & $\$ 1.11$ & $\$ 0.29$ \\
Tuesday & $\$ 1.22$ & $\$ 1.91$ & $\$ 1.60$ & $\$ 0.47$ & $\$ 0.31$ & $\$ 0.98$ & $\$ 2.19$ & $\$ 3.17$ & $\$ 2.42$ & $\$ 1.04$ & $\$ 0.48$ \\
Wednesday & $\$ 1.46$ & $\$ 2.61$ & $\$ 2.06$ & $\$ 0.71$ & $\$ 0.53$ & $\$ 1.18$ & $\$ 2.33$ & $\$ 4.55$ & $\$ 3.80$ & $\$ 1.35$ & $\$ 0.39$ \\
Thursday & $\$ 1.46$ & $\$ 2.26$ & $\$ 1.85$ & $\$ 0.77$ & $\$ 0.71$ & $\$ 1.16$ & $\$ 2.77$ & $\$ 5.15$ & $\$ 3.92$ & $\$ 1.32$ & $\$ 0.51$ \\
Friday & $\$ 1.10$ & $\$ 3.19$ & $\$ 2.27$ & $\$ 0.99$ & $\$ 1.04$ & $\$ 1.79$ & $\$ 5.55$ & $\$ 7.77$ & $\$ 7.18$ & $\$ 5.76$ & $\$ 2.00$ \\
Saturday & $\$ 2.90$ & $\$ 5.74$ & $\$ 6.17$ & $\$ 4.72$ & $\$ 3.43$ & $\$ 4.39$ & $\$ 5.39$ & $\$ 7.43$ & $\$ 6.90$ & $\$ 3.83$ & $\$ 1.08$ \\
\hline
\end{tabular}

which had annual sales in 2001 of $\$ 2,358,874$, is open from 11 a.m. to 11 p.m. on weekdays and 11 a.m. to midnight on weekends and draws a variety of customers including shoppers, couples, and families. The restaurant has a full-service bar and prides itself on its freshly prepared Mexican food. As is typical in many restaurants, the subject store is very busy for weekend dinners and lunches and customers often wait for a table for over an hour during these periods. The restaurant is particularly slow on weekdays before noon and between 2 p.m. and 5 p.m., and after 8 p.m. on Sundays through Thursdays.

The restaurant has three sections: the bar (50 seats), the main dining room ( 230 seats), and the patio (60 seats). This study focused on the main dining room because of the diversity of business in the bar (both drinks and meals) and the seasonality of the patio. Nearly all of the tables in the main dining room (53 of 56) were 4-top tables, the remaining three 
tables were 6-tops.

First we established the baseline performance of the restaurant. We collected two months of transaction data from their Point of Sale (POS) system and used this data to calculate the average check, the revenue per available seat hour (RevPASH; Table 1), the seat occupancy (Table 2), the party size composition (Table 3), and the mean and standard deviation of meal duration (Table 4) by hour and day of week. For a full description of the calculations and a discussion of the results, see Kimes (2004).

\section{REVENUE IMPACT}

Given a fixed set of menu prices, RevPASH can be increased by either reducing dining duration, increasing the average check, or increasing seat occupancy. Because an increase in RevPASH has the greatest impact during busy periods, only the high demand hours were considered. The restaurant had 11 high demand hours per week (Friday, 5 p.m. to 9 p.m.; Saturday, noon to 2 p.m. and 5 p.m. to 8 p.m.; and Sunday from 1 p.m. to 2 p.m.), but for the sake of simplicity we will illustrate the revenue potential using 10 high demand hours per week.

Table 2: Seat occupancy was calculated by dividing the RevPASH by each hour's average check and multiplying by the average dining duration, in hours-it is an approximate measure of the percentage of time a seat was in use.

\begin{tabular}{lrrrrrrrrrrr}
\hline & \multicolumn{10}{c}{ Hour of Day } \\
\cline { 2 - 11 } & 11 & 12 & 13 & 14 & 15 & 16 & 17 & 18 & 19 & 20 & 21 \\
\hline Sunday & $17 \%$ & $33 \%$ & $40 \%$ & $30 \%$ & $19 \%$ & $22 \%$ & $29 \%$ & $26 \%$ & $14 \%$ & $4 \%$ & $0 \%$ \\
Monday & $14 \%$ & $19 \%$ & $19 \%$ & $14 \%$ & $8 \%$ & $8 \%$ & $22 \%$ & $29 \%$ & $15 \%$ & $8 \%$ & $2 \%$ \\
Tuesday & $8 \%$ & $13 \%$ & $11 \%$ & $3 \%$ & $2 \%$ & $7 \%$ & $15 \%$ & $22 \%$ & $17 \%$ & $7 \%$ & $3 \%$ \\
Wednesday & $10 \%$ & $18 \%$ & $14 \%$ & $5 \%$ & $4 \%$ & $8 \%$ & $16 \%$ & $32 \%$ & $26 \%$ & $9 \%$ & $3 \%$ \\
Thursday & $10 \%$ & $16 \%$ & $13 \%$ & $5 \%$ & $5 \%$ & $8 \%$ & $19 \%$ & $36 \%$ & $27 \%$ & $9 \%$ & $4 \%$ \\
Friday & $8 \%$ & $22 \%$ & $16 \%$ & $7 \%$ & $7 \%$ & $12 \%$ & $39 \%$ & $54 \%$ & $50 \%$ & $40 \%$ & $14 \%$ \\
Saturday & $20 \%$ & $40 \%$ & $43 \%$ & $33 \%$ & $24 \%$ & $30 \%$ & $37 \%$ & $52 \%$ & $48 \%$ & $27 \%$ & $8 \%$ \\
\hline
\end{tabular}

The seat occupancy rarely exceeded $50 \%$. This is primarily due to the poor table mix (most of the tables were tables for four and over half of the parties had only one or two customers).

The seat occupancy rarely exceeded $50 \%$. This is primarily due to the poor table mix (most of the tables were tables for four and over half of the parties had only one or two customers).

Table 3: Party size compositions of weekend lunch and dinner patrons.

\begin{tabular}{lcc}
\hline Party Size & Weekend Dinner $(\%)$ & Weekend Lunch $(\%)$ \\
\hline 1 & 3 & 7 \\
2 & 53 & 45 \\
3 & 21 & 16 \\
4 & 15 & 26 \\
5 & 4 & 1 \\
6 & 1 & 5 \\
7 & 1 & 0 \\
8 & 1 & 0 \\
9 & 1 & 0 \\
\hline
\end{tabular}


Table 4: Friday evening dining duration and average check per party, by party size (based on POS data).

\begin{tabular}{lccc}
\hline Party Size & $\begin{array}{c}\text { Mean of } \\
\text { Dining Duration }\end{array}$ & $\begin{array}{c}\text { Standard Deviation of } \\
\text { Dining Duration }\end{array}$ & $\begin{array}{c}\text { Average } \\
\text { Check }\end{array}$ \\
\hline 1 & $52: 31$ & $25: 02$ & $\$ 24.93$ \\
2 & $49: 56$ & $17: 13$ & $\$ 27.71$ \\
3 & $50: 08$ & $22: 10$ & $\$ 31.38$ \\
4 & $54: 14$ & $18: 37$ & $\$ 42.44$ \\
5 & $54: 26$ & $16: 33$ & $\$ 45.07$ \\
$6+$ & $60: 47$ & $14: 54$ & $\$ 56.30$ \\
\hline
\end{tabular}

Under original conditions (average check of $\$ 12$ and average dining time of 53 minutes), the restaurant could obtain a theoretical annual maximum revenue during peak times of $\$ 1,624,755$ if it had a seat occupancy of $100 \%$ (10 peak-hours x 60 minutes divided by 53 minute dining time x 230 seats $x \$ 12$ average check x 100\% occupancy x 52 weeks/year). The observed peak-period seat occupancy of 50\% would result in an annual revenue potential of $\$ 812,344$ during peak times (10 peak-hours x 60 minutes divided by 53 minute dining time $\times 230$ seats $\times \$ 12$ average check $\times 50 \%$ occupancy $\times 52$ weeks/year). Thus, over one-third (34\%) of its annual revenues were produced during the 10 weekly peak-hours.

Increased peak-period seat occupancy has a noticeable impact on revenue. If peak-period seat occupancy increased to $60 \%$, the annual revenue potential would be $\$ 974,853$ (10 peak-hours x 60 minutes divided by 53 minute dining time $\times$ 230 seats $x \$ 12$ average check x 60\% occupancy x 52 weeks/year) or an incremental annual revenue increase of $\$ 162,476$ over current conditions. This led to our research focus on developing an optimal table mix so that more customers could be served.

\section{IDENTIFYING A BETTER TABLE MIX}

Given the mix of customers in the restaurant, the original table mix clearly seemed too heavily weighted towards large tables. We used the model developed by Thompson (2002) to determine a rough estimate of the best table mix. He presented a simple deterministic method of identifying a table mix that matches capacity to demand. His model is

$$
T_{s}=\frac{T P P_{s}}{\sum_{j \in S} j * T P P_{j}} * S E A T C A P,
$$

where $T_{s}$ is the naive ideal number of tables with $s$ seats; TPP, the number of tables of s seats required per party; SEATCAP, the total seats in the restaurant; and $S$ is the set of allowable table sizes.

Applying these calculations to the data presented in Table 3, and assuming that parties of 1 and 2 are seated at 2tops, parties of 3 and 4 are seated at 4-tops, parties of 5 and 6 are seated at 6 -tops, parties of 7 and 8 are seated at 2- and 6-top tables that are combined, and that parties of 9 are seated at 4- and 6-top tables that are combined, we find that 


$$
\begin{gathered}
T T P_{2}=0.03+0.53+0.01+0.01=0.58 \\
T P P_{4}=0.21+0.15+0.01=0.37 \\
\text { and } \\
T P P_{6}=0.04+0.01+0.01+0.01+0.01=0.08 .
\end{gathered}
$$

Given the restaurant capacity of 230 seats, this yields a recommended mix of 85.5 seats for 2 -top tables (i.e., $T_{2}=85.5$ ), 109.1 seats for 4 -top tables (i.e., $T_{4}=109.1$ ), and 35.4 seats for 6 -top tables (i.e., $T_{6}=35.4$ ). Converting the number of seats into tables, we arrive at a recommended mix of 43 2-tops, 27 4-tops, and six 6-tops in the restaurant.

In reality, however, identifying the best mix of tables cannot be done so simplistically. The reason for this relates to the complex stochastic nature of the restaurant: specifically, the variability in the arrival times, party sizes, and service durations. The variability in arrival rates can cause enormous variation in capacity utilization. For example, on some days the majority of customers may arrive between 6 p.m. and 7 p.m., but on other days most customers might arrive between 7 p.m. and 8 p.m. A model that is able to model the variability in arrival times is clearly warranted. We describe just such a model in the next section.

\section{TABLEMIX MODEL}

Given the stochastic nature of the key variables affecting capacity utilization and RevPASH (namely arrival rates, party size, and meal duration), we decided to use simulation to capture the stochastic nature of the restaurant environment. Other solution methods to table mix optimization such as integer programming were considered, but their deterministic nature did not seem capable of handling this type of problem. We developed a simulation model, which we call TABLEMIX (Thompson, 2002; Thompson \& Verma, 2003), that allows one to simulate the use of restaurant tables over a specified dining period. It is designed primarily as a strategic decision aid, to be used in both initial restaurant design and in periodic reevaluations of a restaurant's design.

TABLEMIX is a stand-alone program, coded in Microsoft's Visual Basic $6.0^{\circledR}$, which runs in the Windows operating environment. Table 5 lists the assumptions, inputs, and output of the TABLEMIX model. We discuss each of the components in the following subsections.

\section{Key Assumptions of TABLEMIX}

TABLEMIX assumes that parties cannot be combined (so that, e.g., two parties of two cannot simultaneously occupy a 4-top table), but parties can be assigned to combinable tables. Combined tables are created by moving separate, but adjacent tables, together to create a table with seating capacity equal to the sum of the seating capacities of its component tables. For example, two adjacent 4-top tables could be combined into an 8-top table. Once the party has completed dining, the combined table is separated to its original component tables. 
TABLEMIX assumes that no parties are in the restaurant at the start of the simulated period. In our case, the main peak dining period is during the 5 p.m. to 9 p.m. period. Since we begin the simulation at 4 p.m. and since dining duration averages less than 1 hour, any parties that started dining prior to 4 p.m. would have little impact on the 5 p.m. to 9 p.m. peak period. Thus, the start-up conditions of the simulation are consistent with the real system.

Another noteworthy assumption is that the physical space required by a table is proportional to the number of its seats. This assumption will not hold for all restaurants, but is reasonable in Chevys' case because the tables must be capable of holding individual platters of a substantial size.

\section{TABLEMIX Inputs}

TABLEMIX allows one to specify the number of days to simulate. We selected 150 days for our analysis, because our testing showed consistent performance results for that time frame. For reference, a 150-day simulation period is approximately the number of busy days that the restaurant would experience during 18 months.

Table 5: The TABLEMIX model is based on certain assumptions and requires specific inputs and produces various utilization and waiting time outputs.

\begin{tabular}{|c|c|}
\hline Assumptions & $\begin{array}{l}\text { - Parties cannot be combined } \\
\text { - Parties may be assigned to tables that are combined (to create a table } \\
\text { with capacity equal to the sum of the capacities of its component tables) } \\
\text { and seated simultaneously } \\
\text { - Poisson arrivals of parties } \\
\text { - Restaurant begins each simulated day empty (i.e., with no parties in } \\
\text { service) } \\
\text { - Space required by tables is proportionally constant to the number of } \\
\text { seats }\end{array}$ \\
\hline Inputs & $\begin{array}{l}\text { - Number of days to simulate } \\
\text { - Maximum number of waiting parties } \\
\text { - Decision rule: give available table to longest waiting party; to largest } \\
\text { acceptable party } \\
\text { - Probability of party sizes } \\
\text { - Mean and standard deviation of dining time, by party size } \\
\text { - Distribution of waiting times (normal or log normal) } \\
\text { - Maximum tolerable wait, by party size (based on actual, not estimated } \\
\text { wait) } \\
\text { - Value, by party size } \\
\text { - Expected number of party arrivals, by } 15 \text {-minute period } \\
\text { - Which tables can be combined with which other tables (to create larger } \\
\text { tables) } \\
\text { - Table configuration: number of each size table in inventory } \\
\text { - Valid table sizes to use* }\end{array}$ \\
\hline Outputs & $\begin{array}{l}\text { - Utilization by resource type, by } 15 \text {-minute period (i.e., by table sizes } \\
\text { and by seats): graphical and tabular } \\
\text { - By party size: \# served, \# lost, average wait, longest wait per day, } \\
\text { \# customers lost, value lost } \\
\text { - Total customers served and lost; total value achieved and lost; customers } \\
\text { served per available seat; seat utilization (or occupancy) }\end{array}$ \\
\hline
\end{tabular}

${ }^{*}$ Used only in the TABLEMIX-OPT, the search engine for optimal table mixes. 
TABLEMIX allows one to limit the number of waiting parties. This limit may be based on the size of the bar, lobby, or parking area. In our case, we selected a limit of 30 parties.

TABLEMIX allows one to select the rule used in assigning waiting parties to available tables. An available table can be assigned to the party waiting the longest or to the largest waiting party. Our experience has been that the former rule provides the best service during less busy periods, but that the latter rule is much more effective in maximizing the utilization of the restaurant during peak demand periods. Since we are focusing on the peak demand periods in this analysis, we chose the latter table assignment rule. We note, however, that this rule can lead to very different service levels by party size when demand is greater than capacity. For example, if the tables seat 2, 4, or 6 patrons, the waits for parties of 2, 4, or 6 will be much lower than the waits for parties of 1,3 , or 5 .

There are a number of inputs for each party size: the probability of that size party, the mean and standard deviation of dining time, the distribution of dining times (normal or log normal), the maximum wait tolerated, and the value of the party. We used a maximum wait of 60 minutes for all party sizes. All data inputs to TABLEMIX were based on the actual data presented in Tables 1-5.

TABLEMIX requires that one provide information on the number of parties expected to arrive, by 15 -minute period for a peak window of a user-defined duration. This arrival information can be based on historical data or from forecasts. The estimated arrival rates by period are used with an exponential distribution to simulate the actual party arrivals. Party size is then randomly determined using the probabilities of the different party sizes.

The last TABLEMIX inputs are the number of each size table that exists in the restaurant and which tables can be combined with which other tables. One can use TABLEMIX to simulate the current configuration of the restaurant or, by changing the mix of tables, to simulate possible configurations.

\section{TABLEMIX Outputs}

The outputs of TABLEMIX fall into three categories: resource utilization, customer service, and aggregate measures. TABLEMIX presents the utilization of each resource (i.e., each size of table and seats), by 15-minute time period, both in tabular and graphical formats. Customer service measures, which are provided for each party size, include the number of customers served and lost, the value of customers served and lost, and the average and maximum waits. Aggregate performance measures are seat utilization (or occupancy), number of customers served per available seat, RevPASH, total number of customers served and lost, the total value of customers served and lost, and the average customer waiting times.

\section{MODEL VALIDATION RESULTS}

Figure 2 shows the results that we obtained when simulating the restaurant's original table mix. The horizontal axis shows 15-minute periods beginning at the noted times, while the vertical axis is the utilization of the particular resource. Recall that the restaurant had 53 4-top and 3 6-top tables. Resource utilization increased from 4 p.m. to 6 p.m., remains at peak or near-peak utilization from 6 p.m. to 8 p.m., and then declined after 8 p.m. 
The graphical results correspond reasonably well with the actual results reported in Table 2. Actual seat occupancies for Friday over the hours from 5 p.m. to 9 p.m. were 43\%,61\%, 52\%, and 42\%, respectively (Table 2). Our simulated occupancy is higher than the actual because we incorporate the total service duration into our simulation. Parts of the service duration-most notably seating the party and bussing the table-occur when the customers are not, in fact, at the table and so do not show up in the observed utilization values. In the time study that we performed at the restaurant, customers were not at the table for about 3:40 minutes out of the total service cycle time of 56:58 minutes. This represents $6.4 \%$ of our total simulated time, which is very similar to the difference between the actual and our simulated seat occupancy. In our simulation of the existing configuration, we arrived at a RevPASH value of $\$ 6.44$ over the hours of 5 p.m.

Figure 2: The simulated seat and table occupancy of the current table mix was largely the same as the actual seat and table occupancy.

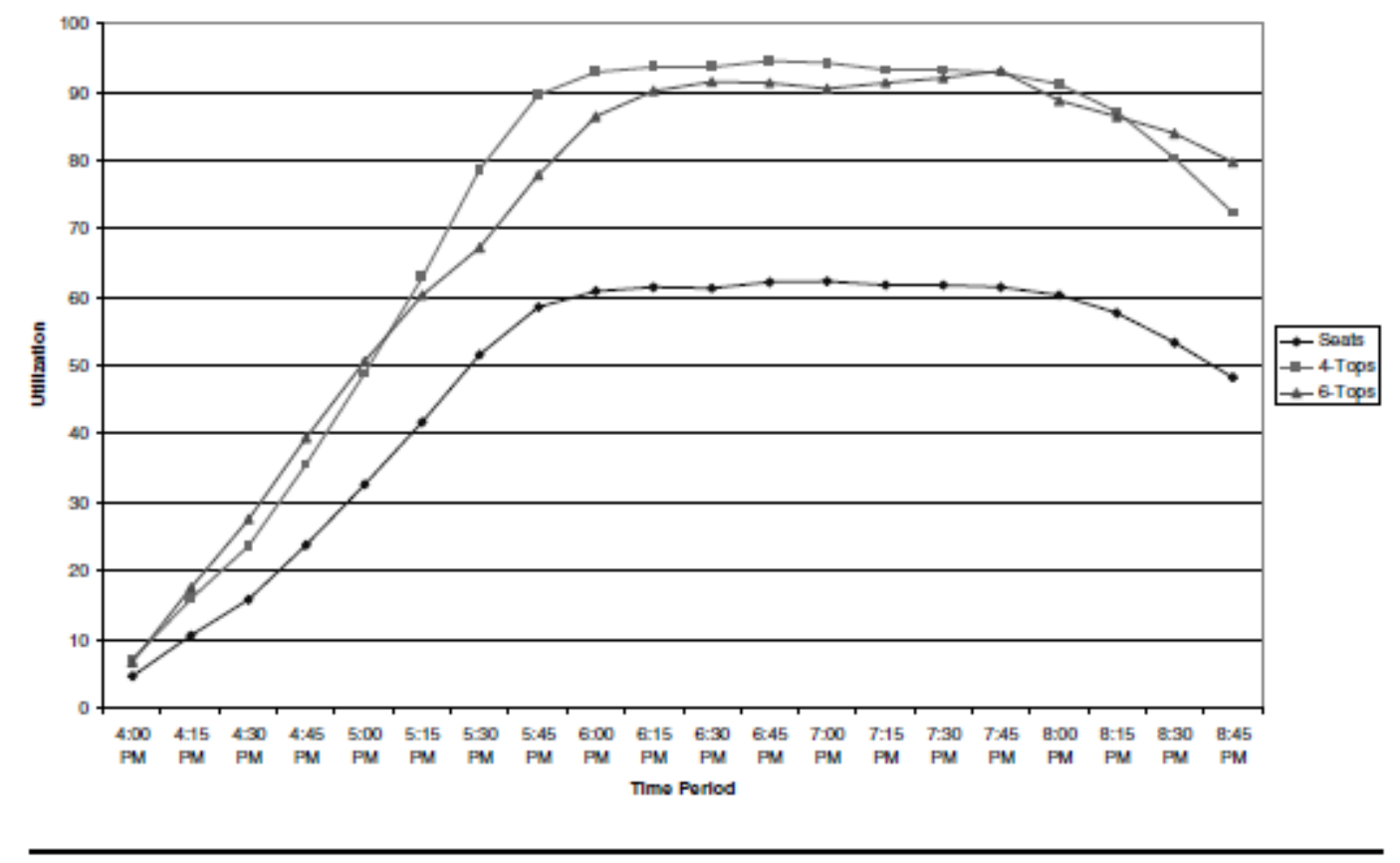

to 9 p.m. This again compares well with the actual average of $\$ 6.57$ for the same period (from Table 1 ). Finally, because we used actual customer counts as an input to the model, we expected that the current configuration would serve all customers arriving in the 4 p.m. to 9 p.m. period. On average in the simulation, the current table mix served 593.2 of the 594.9 customer arrivals, or within $0.27 \%$ of the expected result. Our overall evaluation, then, was that TABLEMIX was providing results that were consistent with actual results. This enabled us to use the tool to evaluate the performance that could be expected under other table mixes and customer volumes.

\section{TABLEMIX Enumerator}

The TABLEMIX enumerator, TABLEMIX-ENUM, is designed to find the best mix of tables. It does this by examining all feasible combinations of table sizes and using the TABLEMIX simulation to evaluate each table mix. The additional parameters used in TABLEMIX-ENUM are which of the table sizes can be used. In the Chevys case, the restaurant had 230 seats and could use 2-, 4-, or 6-seat tables. This resulted in 1,160 distinct table mixes to be evaluated, each of which used 
the full complement of 230 seats.

\section{Enumeration Results}

We investigated the effect of altering the table mix, both under the observed level of customer demand and under increased levels of demand. We did this by running TABLEMIX-ENUM for demand volumes equal to $100 \%, 110 \%, \ldots, 180 \%$ of the current level. In this testing, we found that the best mix of tables was dependent on the level of customer demand. At very high demand levels (i.e., more than $50 \%$ higher than the current level), no mix of 2-, 4-, and 6-top tables totaling

Table 6: RevPASH values for ranked ordered table mixes, expressed as a percentage of the maximum RevPASH (averaged across a demand volume range of $100 \%$ to $150 \%$ of the current level).

\begin{tabular}{lc}
\hline Table-Mix Decile & RevPASH $(\%$ of Maximum) \\
\hline 1 & 99.05 \\
2 & 98.14 \\
3 & 97.24 \\
4 & 96.40 \\
5 & 95.40 \\
6 & 94.39 \\
7 & 92.58 \\
8 & 89.93 \\
9 & 84.17 \\
10 & 66.98 \\
\hline
\end{tabular}

230 seats can serve the customers adequately. When demand was very high, we saw the mix of tables change so that fewer of the most valuable customers would be lost (recall, from Table 4, that customers in different sized parties spend different amounts). We decided to find a mix of tables that performed well across demand levels of $100 \%$ to $150 \%$ of the current level. Across this range of customer volumes, the best mix of tables for the restaurant is 432 -tops, 27 4-tops, and six 6-tops. This table mix yielded the highest average RevPASH of $\$ 8.01$ (averaged across the volumes of $100 \%, 110 \%, \ldots$, $150 \%$ of current demand).

Interestingly, a high proportion of the table mixes performed well across the range of customer volumes. Table 6 , which reports the performance of the table mixes ranked ordered by declining RevPASH, shows that $10 \%$ of the possible table mixes yielded RevPASH within $0.95 \%$ of the highest reported. Of the 1,160 feasible table mixes, the current table mix was ranked 935th on the basis of its performance across the range of demand values, yielding $89.6 \%$ of the RevPASH possible with the best table mix.

Having established the recommended table mix for the restaurant, we then proceeded to compare the performance of that mix to the performance of the restaurant's current table mix across the range of customer volumes. Figure 3 shows the achieved RevPASH for the Friday 5 p.m. to 9 p.m. period for the current table mix and for our recommended table mix. The current table mix loses customers (i.e., has a lower achieved RevPASH) with any increase in customer volume, though the loss becomes very pronounced with demand levels more than $20 \%$ higher than the current level. The plateau 
observed in the achieved RevPASH of the current mix indicates that the restaurant, as currently configured, is operating at close to its maximum capacity. However, the nearly linear increase in achieved RevPASH of the proposed table mix indicates that the proposed mix has a much higher effective capacity. Increasing the effective capacity of the restaurant enables more customers to be served with the same level of service.

Figure 3: The achieved RevPASH of the best table mix increases nearly linearly with an increase in customer volume (for demand volumes up to $50 \%$ higher than current), while the achieved RevPASH of the current table mix plateaus.

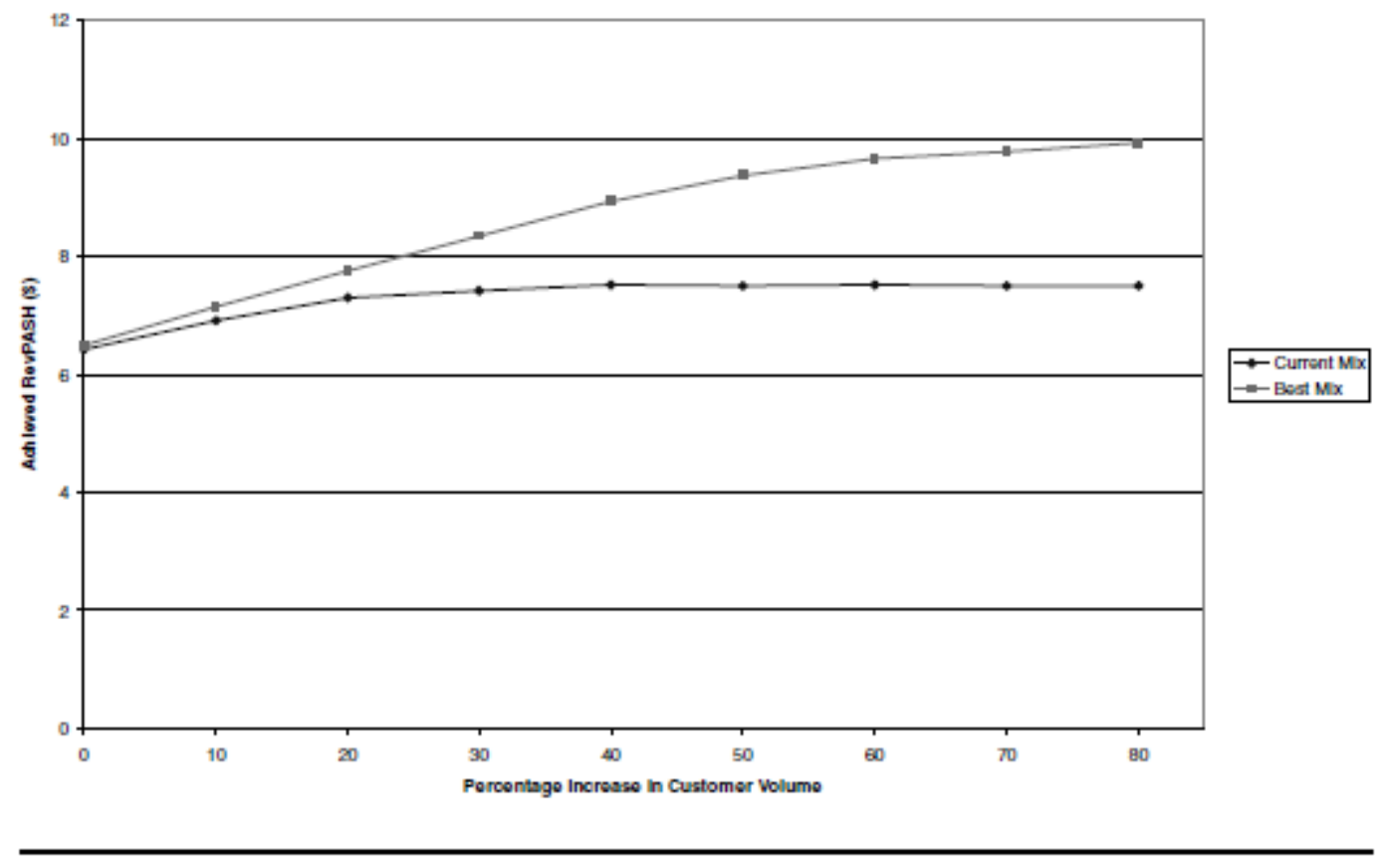

Figure 4 shows the average wait experienced by parties for the 5 p.m. to 9 p.m. period for the current table mix and for our recommended table mix. These waits are averages across all parties-some waits are much longer. Essentially, their current table mix is running at capacity-any increase in customer volume has a marked increase in waits. The proposed mix curve has much lower waiting times than the current mix (Figure 4). Again, this is because our proposed mix is providing more effective capacity with the same number of seats, simply by providing a better balance of table capacity with table demand.

Through demand growth of at least 30\%, our proposed mix yields waiting times that are the same or lower than that observed for the current table mix under the current level of customer demand. Once the demand increases to more than $30 \%$ higher than the current level, the waiting times for the recommended table mix exceed the existing wait times for the existing table mix, though they are still far below what the waiting times would be with the current table mix under the increased demand.

Assuming customer wait tolerance is the prime limiting factor in demand, then if the restaurant changes to the recommended table mix, they can increase the number of customers served by about $30 \%$, without increasing the wait experienced by customers. We believe this is the vein in which our results should be viewed, because the restaurant is in 
a highly competitive area and there are a number of alternatives available to potential customers. We believe that switching to the recommended table mix provides the restaurant the opportunity to increase RevPASH during the peak demand periods by about 30\%, since about 30\% more customers can be served without altering the waits experienced in the current configuration. Increasing RevPASH by $30 \%$ in the 11 peak-hours per week translates to an increase in weekly sales of $\$ 3,780$, or over $\$ 200,000$ per year for this particular restaurant.

Figure 4: The average waiting time (in minutes) for parties was lower for the recommended table mix even with an increase in customer volume of up to $30 \%$, in comparison to that for the current mix under the current customer volume.

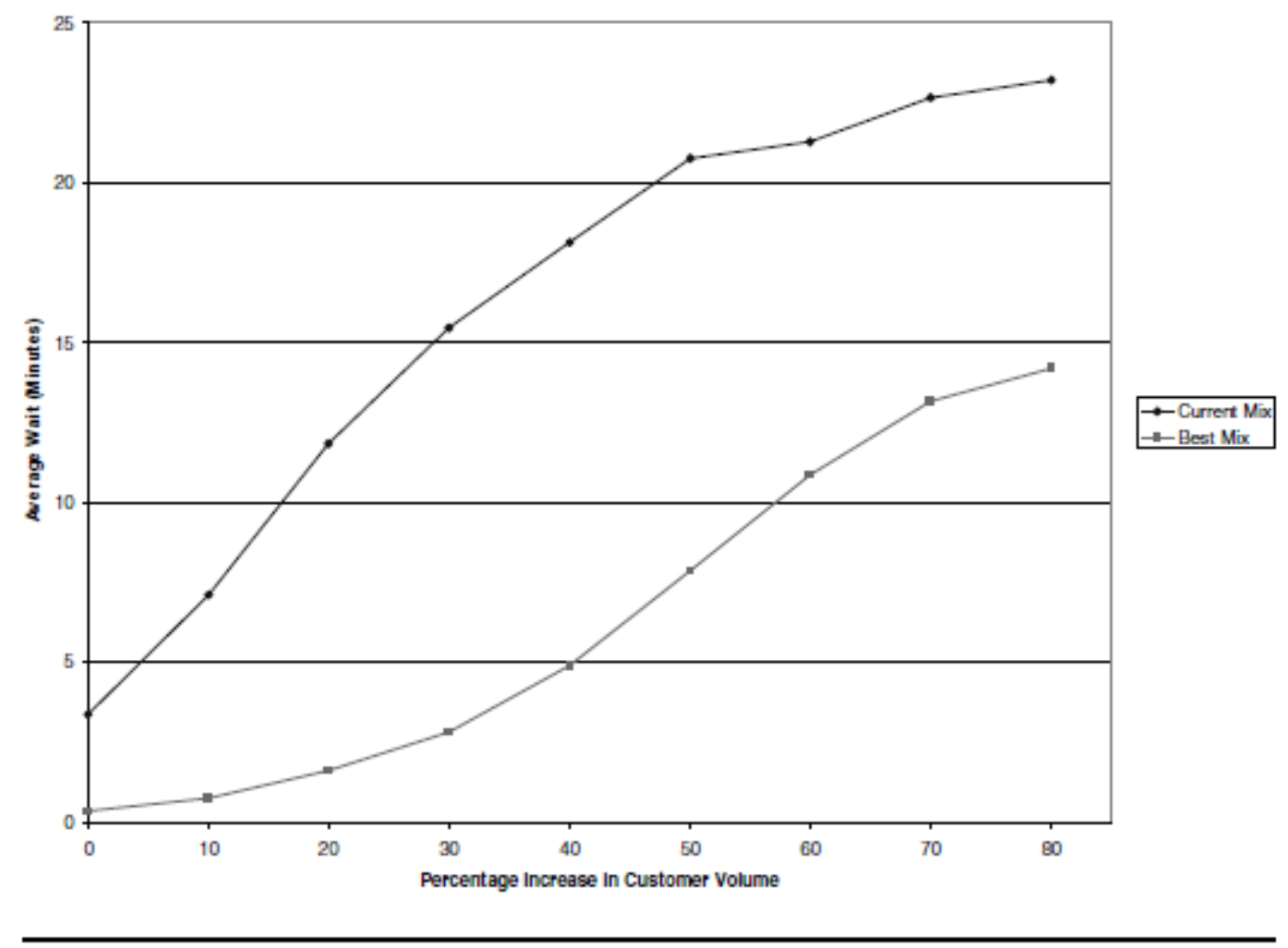

\section{IMPLEMENTATION}

Chevys' management gave the optimal table mix to a restaurant designer and asked her to redesign the restaurant to accommodate the optimal table mix while maintaining both customer and employee comfort. They settled on a design that contained 39 2-tops, 35 4-tops, and 26 -tops. Their table mix differed slightly from the one recommended because of design considerations. Our simulation results suggest that this mix should perform within about $1.3 \%$ of the recommended mix.

Restaurant management and staff were trained on revenue management principles and the impact they would have on the restaurant and each employee. The increased number of tables required increases in staffing levels and ancillary equipment (plateware, tablecloths, etc.). The server stations were reconfigured, the tables were renumbered and additional servers were hired to help cover the additional tables. In addition, because the number of customers was expected to increase the workload of the kitchen, three additional positions were added for peak periods. The additional 
labor cost was approximately $\$ 15,000$ per year.

Construction began on February 18,2002 (after the Valentine's Day rush) and was completed on February 28, 2002. All work was completed between midnight and 9 a.m. so that regular operations were not affected. The cost of the remodeling was approximately $\$ 50,000$ with an additional $\$ 1,500$ for one-time ancillary equipment expenses.

About 2 months after implementation, we went back to the restaurant to measure operational performance. Seat occupancy during peak periods had increased from $50 \%$ to $59 \%$, the average dining duration had dropped from 53 minutes to 51 minutes, and the standard deviation had dropped from near 23 minutes to just over 15 minutes. The corresponding reduction in the coefficient of variation (from approximately 0.43 to 0.29 ) can have a positive effect on revenue: our preliminary studies show that a decrease in the coefficient of variation (from 0.5 to 0.3 ) can increase revenue by $3.6 \%$.

In addition, RevPASH during peak periods had increased from $\$ 5.85$ to $\$ 6.32$. Although the results seemed promising, we wanted to ensure that the revenue increases were due to the revenue management project and not from market conditions. To do this, we analyzed the financial impact on the restaurant by comparing the operational results from the 6 weeks before the remodeling (12/26/01 - 2/12/02) to a similar period 1 month after the remodeling (3/27/02 - 5/8/02) for the test restaurant and for two other Chevys in the same market. The subject restaurant recorded a $5.7 \%$ decrease in revenue from 2001 to 2002 for the pretest period while the control restaurants experienced a $10.6 \%$ decrease for the same time period. For the posttest period, revenue increased by $2.0 \%$ in the test restaurant from 2001 to 2002 while revenue decreased in the control restaurants by $8.0 \%$. Based on this, the test restaurant had an increase in revenue of $7.7 \%$ from pretest to posttest while the control restaurants had an increase of $2.6 \%$, for a net increase of $5.1 \%$ attributable to revenue management.

Based on this, Chevys is predicting a $\$ 120,000$ annual increase in revenue for the test restaurant, which would result in an approximately $45 \%$ projected increase in earnings before interest, taxes, depreciation, and amortization (EBITDA) flow through and an 11-month payback period. Although this revenue improvement is only about $73 \%$ of the potential revenue increase $(\$ 120,000 / \$ 162,476)$, the revenue impact was substantial. The 3 -year NPV (assuming a $10 \%$ cost of capital) of their $\$ 50,000$ investment was about $\$ 211,000$. Since Chevys has over 100 restaurants, if the restaurant we studied was typical, the potential revenue of optimizing table mixes would be substantial.

\section{SUMMARY AND CONCLUSION}

In this article, we developed and applied a simulation-based table enumeration system that allowed us to determine the optimal table mix for a 230-seat restaurant. By redesigning their table mix, redesigning their service delivery process, and focusing on RevPASH, the restaurant was able to achieve a $5.1 \%$ increase in revenue.

While the simulation model that we developed works well for identifying the optimal table mix, the time involved with the complete enumeration of all possibilities is excessive. In a larger restaurant, with a wide variety of possible table sizes, the problem would become even more unwieldy. The one heuristic we tested worked well (in fact, it identified the best table mix), but we are unsure as to how well it would work in other situations. Other heuristics could also be 
developed to address this problem and their relative performance could be assessed through the use of our enumeration model.

The sensitivity of various heuristics to various parameters such as the standard deviation of dining time, the variation in arrival rate, and the variability of party size should also be tested. Again, the enumeration model could be used to assess their effectiveness.

In addition, we tested our enumeration model in a casual upscale restaurant. Different results might be obtained for different styles of restaurants (i.e., fine dining, family, fast food). Also, the development of the optimal supply mix could be applied to a number of other industries including the airline industry (the optimal mix of airplane sizes), the selfstorage industry (the optimal mix of unit sizes), the meeting space rental industry (the optimal mix of room sizes), and the hotel industry (the optimal mix of suites and other room configurations).

A number of other research questions are suggested by our work. For example, what is the effect of errors in forecasting the number of customers, the mix of customers, and distribution of dining times? That is, do the size and/or magnitude of the forecast errors change the optimal table mix, the best policy for combining tables, and the best policy for seating customers? How sensitive are the revenue improvements to forecast errors? When should the existing table mix be changed? That is, if the number and mix of customers is changing, how should the restaurant determine the best time to adjust the table mix? It is our hope that researchers may begin to examine such issues.

In summary, we have shown how the optimal supply mix for a service firm may be just as important, if not more important, than the optimal demand mix. If the supply mix does not match the demand mix profile, any revenue management efforts will result in suboptimal results. In this article, we have shown how improving the supply mix of a mid-sized restaurant increased revenue by $5.1 \%$ per year. The revenue potential of an optimal supply mix in the restaurant industry and other industries is substantial and worthy of further study. [Received: January 2003. Accepted: December 2003.]

\section{REFERENCES}

Baker, T. K., \& Collier, D. A. (1999). A comparative revenue analysis of hotel yield management heuristics. Decision Sciences, 30, 239-256.

Belobaba, P. P. (1989). Application of a probabilistic decision model to airline seat inventory control. Operations Research, $37,183-197$.

Bertsimas, D., \& Perakis, G. (2001). Dynamic pricing: A learning approach. Working Paper, Operations Research Center, OR 355-01, MIT.

Bertsimas, D., \& Shioda, R. (2003). Restaurant revenue management. Operations Research, 51, 472-486.

Carroll, W. J., \& Grimes, R. C. (1995). Evolutionary change in product management: Experiences in the car rental industry. Interfaces, 25(5), 84-104.

Gallego, G., \& van Ryzin, G. (1994). A multi-product dynamic pricing problem and its application to network yield management. Operations Research, 45, 24-41.

Hanks, R. B., Noland, R. P., \& Cross, R. G. (1992). Discounting in the hotel industry: A new approach. Cornell Hotel and Restaurant Administration Quarterly, 33(3), 40-45. 
Kimes, S. E. (1999). Implementing restaurant revenue management: A five-step approach. Cornell Hotel and Restaurant Administration Quarterly, 34(3), 16-21.

Kimes, S. E. (2004). Revenue management: Implementation at Chevys Arrowhead. Cornell Hotel and Restaurant Administration Quarterly, 45(1), 52-67.

Kimes, S. E., Barrash, D. I., \& Alexander, J. E. (1999). Developing a restaurant revenue-management strategy. Cornell Hotel and Restaurant Administration Quarterly, 34(5), 18-30.

Kimes, S. E., \& Chase, R. B. (1998). The strategic levers of yield management. Journal of Service Research, 2(1), 156-166.

Kimes, S. E., Chase, R. B., Choi, S., Ngonzi, E. N., \& Lee, P. Y. (1998). Restaurant revenue management. Cornell Hotel and Restaurant Administration Quarterly, 40(3), 40-45.

Kimes, S. E., \& Wirtz, J. (2002). Perceived fairness of demand-based pricing for restaurants. Cornell Hotel and Restaurant Administration Quarterly, 41(1), 338.

Kimes, S. E., \& Wirtz, J. (2003). Has revenue management become acceptable? Findings from an international study on the perceived fairness of rate fences. Journal of Service Research, 6(2), 125-135.

Kimes, S. E., Wirtz, J., \& Noone, B. M. (2002). How long should dinner take? measuring expected meal duration for restaurant revenue management. Journal of Revenue and Pricing Management, 1(3), 220-233.

Klassen, K. J., \& Rohleder, T. R. (2001). Combining operations and marketing to manage capacity and demand in services. The Service Industries Journal, 21(2), 1-30.

Littlewood, K. (1972). Forecasting and control of passenger bookings. 1972 AGIFORS Symposia, Alliance Group of the International Federation of Operational Research Scientists, 95-117.

Lovelock, C. H. (1992). Strategies for managing capacity constrained service organizations. In C. H. Lovelock (Ed.), Managing Services: Marketing, Operations and Human Resources (2nd ed.). Englewood Cliffs, NJ: Prentice-Hall, 154168.

McGill, J. I., \& van Ryzin, G. J. (1999). Revenue management: Research overview and prospects. Transportation Science, $33,233-256$.

Ng, I. C. L., Wirtz, J., \& Lee, K. S. (1999). The strategic role of unused service capacity. Internationaljournal of Service Industry Management, 10(2), 211- 238.

Rexing, B., Barnhart, C., Kniker, T., Jarrah, A., \& Krishnamurthy, N. (2000). Airline fleet assignment with time windows. Transportation Science, 34(1), 1526-5447.

Sasser, E. E. (1976). Match supply and demand in service industries. Harvard Business Review, (November-December), 133-140.

Smith, B. A., Leimkuhler, J. F., \& Darrow, R. M. (1992). Yield management at American Airlines. Interfaces, 22(1), 8-31.

Thompson, G. M. (2002). Optimizing a restaurant's seating capacity: Used dedicated or combinable tables? Cornell Hotel and Restaurant Administration Quarterly, 43(4), 48-57.

Thompson, G. M. (2003). Optimizing restaurant-table configurations: Specifying combinable tables. Cornell Hotel and Restaurant Administration Quarterly, 44(1), 53-60.

Thompson, G. M., \& Verma, R. (2003). Computer simulation in hospitality teaching, practice and research. Cornell Hotel and Restaurant Administration Quarterly, 44(2), 85-93.

Weatherford, L. R. (1995). Length-of-stay heuristics: Do they really make a difference? Cornell Hotel and Restaurant Administration Quarterly, 36(6), 70-79.

Weatherford, L. R., \& Kimes, S. E. (2003). A comparison of forecasting methods for hotel revenue management. International Journal of Forecasting, 19, 401-415.

Wickham, R. R. (1995). Evaluation of forecasting techniques for short-term demand of air transportation. Flight Transportation Lab, MIT Thesis. 
Sheryl E. Kimes is a Professor of Operations Management at the Cornell University School of Hotel Administration. She has her PhD in operations from the University of Texas-Austin and specializes in revenue management. Her research has appeared in Journals such as Interfaces, the Cornell Hotel and Restaurant Administration Quarterly and the Journal of Operations Management. She has been at Cornell and teaches courses in yield management, restaurant revenue management and graduate quantitative methods. She has given seminars on revenue management for hotels around the world and has consulted with a number of companies including Starwood- Asia-Pacific, Troon Golf, American Airlines, the International Association of Assembly Managers, Walt Disney World Resorts and Chevys FreshMex Restaurants.

Gary M. Thompson is a Professor of Operations Management and Executive Director of The Center for Hospitality Research in the School of Hotel Administration at Cornell University. He holds a BSc from the University of New Brunswick, an MBA from the University of Western Ontario and a PhD in operations management from The Florida State University. His research has appeared in Decision Sciences, Interfaces, Journal of Operations Management, Management Science, Naval Research Logistics, Operations Research, and other journals. He is also the founder of Thoughtimus, Inc., a small software company focused on scheduling tools and services. 